\title{
A RETROSPECTIVE STUDY OF SHORT IMPLANTS WITH TWO DIFFERENT SURFACES PLACED IN LATERAL ASPECTS OF THE MAXILLA WITH LIMITED HEIGHT OF ALVEOLAR RIDGE: 36 MONTHS OF FOLLOW-UP
}

\author{
Paweł Kubasiewicz-Ross, Jakub Hadzik, Artur Pitułaj \\ Department of Oral Surgery, Medical University of Wroclaw, Wroclaw, Poland
}

\begin{abstract}
INTRODUCTION: The problem of implant rehabilitation for maxillary atrophy is crucial. It involves the use of short implants or sinus-lift and the establishment of standard implants.

ОвJеCTIVEs: To evaluate the efficacy of short ( $6 \mathrm{~mm}$ long) dental implants of two different surfaces in 36 months of follow-up.

MATERIAL AND METHODS: Thirty generally healthy patients with good oral hygiene, treated with short implants (6 $\mathrm{mm}$ long and $4 \mathrm{~mm}$ in diameter) due to individual missing teeth in the lateral aspects of maxilla were qualified for the study. Patients were divided into two equal groups. The first group consisted of patients treated with sandblasted and additionally etched (SLA) implants, whereas in the second group, electrochemically hydroxyapatite-coated implants were used. Periodontal indexes such as pocket depth probing (PPD), height of keratinized gingiva (HKT), recession depth/width, and clinical attachment level were evaluated on the day of surgery and after 36 months. Additionally, the orthopantomographic X-ray was carried out in order to assess the marginal bone loss (MBL).

Results: The success rate in both groups were $100 \%$. The mean MBL was $0.34 \mathrm{~mm}$ for SLA and $0.33 \mathrm{~mm}$ for hydroxyapatite (HA) implants, with no statistically important differences. The only statistically important differences were seen in PPD and HKT parameters: $2.53 \pm 0.83 \mathrm{~mm}$ vs. $1.47 \pm 0.64 \mathrm{~mm}$, and $2.27 \pm 0.96 \mathrm{~mm}$ vs. 3.30 $\pm 1.08 \mathrm{~mm}$ for SLA and HA implants, respectively.

ConcLusions: Short implants can be considered as a predictable method of treatment in the lateral aspects of maxilla. There are no differences in survival rate between SLA- and HA-surfaced implants in 36 months of follow-up.
\end{abstract}

KEY WORDS: retrospective study, short implant, alveolar bone loss.

J Stoma 2020; 73, 1: 11-14

DOI: https://doi.org/10.5114/jos.2020.94169

\section{INTRODUCTION}

Implantological treatment of patients with reduced bone volume still remains a significant clinical challenge. In these cases, there are two treatment theories. The first concept, historically first, indicates the need to improve bone base conditions by using regenerative surgical techniques in order to enable the insertion of implants of traditional size. The second concept postulates the usage of a short or ultra-short implant [1-5].

However, the definition of short implants is still not unificated. Tawil and Younan [4] considered implants

JOURNAL OF STOMATOLOGY CZASOPISMO STOMATOLOGICZNE

AdDress For CORRESPONDENCE: Dr. Paweł Kubasiewicz-Ross,

Department of Oral Surgery, Wroclaw Medical University, 26 Krakowska St., 54-207 Wroclaw, Poland, e-mail: pawelkubasiewicz@wp.pl 
lower than $10 \mathrm{~mm}$ in length as short, while Nisand and Renouard [6] described implants $\leq 8 \mathrm{~mm}$ in length as short and implants $\leq 5 \mathrm{~mm}$ as ultra-short. The concept behind treatment with short implants is based on new, more active types of dental implant surfaces characterized by higher osteoconductive potential.

There are numerous concepts to improve osteoconductive features of the implant surface. The most commonly used, having extensive literature documentation is the titanium surface, which is sandblasted and additionally etched (SLA). Nowadays, it is considered as a gold standard, to which other types of surfaces that are subjected for experimental evaluation should refer [7].

In the nineties of the last century, titanium implants coated with hydroxyapatite began to be used. At first, hydroxyapatite (HA) was applied to the surfaced with plasma coating. Currently, electrochemical deposition is used for this purpose, resulting in more porous crystal structure with even higher osteoconductive potentials $[8,9]$.

\section{OBJECTIVES}

To provide a retrospective comparative analysis of two short implants with different surfaces in 36 months of follow-up observation.

\section{MATERIAL AND METHODS}

Thirty generally healthy patients, 16 women with a mean age of $45.2 \pm 21.2$, previously treated with short implants (6 $\mathrm{mm}$ long and $4 \mathrm{~mm}$ in diameter) due to individual missing teeth in the molar region of maxilla were qualified for the study. Other inclusion criteria included minimal apico-coronal height of alveolar ridge with $6 \mathrm{~mm}$ in the region of the implant insertion in presurgical qualification, minimal width of the alveolar ridge with 6-7 $\mathrm{mm}$ in the region of interest, approximal plaque index $(\mathrm{API}) \leq 35$, and plaque index $(\mathrm{PI}) \leq 25$. The exclusion criteria that disqualified patients from the study were previous graft procedures in the area of interest and systemic or local diseases that could compromise healing or osteointegration. Smokers and patients with bruxism were excluded from the study as well.

Patients were divided into two equal groups. The first group (G1) consisted of patients with SLA implants (OsseoSpeed $^{\mathrm{TM}}$, Dentsply, New York, USA), whereas the second group (G2) included patients with electrochemically hydroxyapatite-coated SGS implants (SGS Dental Implant System Holding St. Gallen, Switzerland). Each patient had single implant provided in a minimally invasive, transmucosal implant surgery. The implants were non-submerged, and 3-months loaded. The assessment was based on clinical examination using pocket depth probing (PPD), which was measured around the implants in four measurement points, with height of keratinized gingiva (HKT), clinical attachment level (CAL), and the recession depth/width (RD/RW). The evaluation of HKT was performed on the day of surgery $\left(\mathrm{T}_{0}\right)$ and after 36 months $\left(\mathrm{T}_{36}\right)$ from the implants' loading. The rest of periodontal indexes were verified after 36 months of loading. Additionally, on $\mathrm{T}_{0}$ and $\mathrm{T}_{36}$, the orthopantomographic X-ray picture (OPG) (Galil$\operatorname{eos}^{\circledR}$ D3437, Sirona Dental, Erlangen, Germany) along with the clinical examination were performed in order to assess the marginal bone loss (MBL). The MBL was calculated as follows. First, dimensions were calibrated by known parameters of implant diameter and length. Starting from the implant shoulder, distances were measured to the mesial and distal points of bone to implant contact, parallel to the implant axis. All measurements were done by AP, a junior member of the study team, who was not involved directly in performing implant surgeries and had no knowledge about the type of implant evaluated. Statistica version 13.3 (StatSoft, Warsaw, Poland) was used to perform statistical analysis. Initially, the Shapiro-Wilk test was applied in order to evaluate normality of the distribution. Then, statistically important differences were tested using Student $t$-test.

\section{RESULTS}

The effectiveness of the implant therapy in 36 months of follow-up was $100 \%$. All 30 implants survived for 36 months. Furthermore, the absence in implant's mobility, pain, paresthesia, and inflammatory process as well as lack of resorption features of the bone structure in the direct vicinity of the implants of both groups were reported.

\section{GROUP $1(G 1)$}

The mean measurement of HKT was $3.67 \pm 1.57 \mathrm{~mm}$ $\left(\mathrm{T}_{0}\right)$ and was reduced to $2.27 \pm 0.96 \mathrm{~mm}$ after 36 months $\left(\mathrm{T}_{36}\right)$. PPD, CAL, RD, and RW investigated in $\mathrm{T}_{36}$ were $2.53 \pm 0.83 \mathrm{~mm}, 3.07 \pm 1.39 \mathrm{~mm}, 0.67 \pm 1.23$, and 1.27 $\pm 1.87 \mathrm{~mm}$, respectively. The mean $\mathrm{MBL}$ was 0.34 $\pm 0.25 \mathrm{~mm}$

\section{GROUP 2 (G2)}

The mean measurement of HKT was $3.40 \pm 1.26 \mathrm{~mm}$ $\left(\mathrm{T}_{0}\right)$ and was reduced to $3.30 \pm 1.08 \mathrm{~mm}$ after 36 months $\left(\mathrm{T}_{36}\right)$; however, it was significantly higher than in G1 in $\mathrm{T}_{36}$. PPD, CAL, RD, and RW prodded in $\mathrm{T}_{36}$ were 1.47 $\pm 0.64 \mathrm{~mm}, 2.02 \pm 1.01 \mathrm{~mm}, 0.67 \pm 0.72$, and 0.93 $\pm 0.96 \mathrm{~mm}$, respectively. The mean $\mathrm{MBL}$ was $0.33 \pm$ $0.36 \mathrm{~mm}$. The only statistically important differences between G1 and G2 group in $\mathrm{T}_{36}$ observation was in PPD and HKT36 parameters: $2.53 \pm 0.83 \mathrm{~mm}$ vs. 1.47 $\pm 0.64 \mathrm{~mm}$, and $2.27 \pm 0.96 \mathrm{~mm}$ vs. $3.30 \pm 1.08 \mathrm{~mm}$, respectively (Table 1 ). 
TABLE 1. The intra-group statistical analyses of the achieved results. Results significantly different are marked in bold

\begin{tabular}{|c|c|c|c|c|c|c|c|c|}
\hline \multicolumn{2}{|c|}{ Implant therapy } & $\mathrm{HKT}_{0}$ & $\mathrm{HKT}_{36}$ & $\mathrm{RW}_{36}$ & $\mathbf{R D}_{36}$ & $\mathrm{PPD}_{36}$ & $\mathrm{CAL}_{36}$ & MBL \\
\hline \multirow[t]{4}{*}{ SLA } & Min & 0.00 & 0.00 & 0.00 & 0.00 & 1.00 & 1.00 & 0.10 \\
\hline & $\operatorname{Max}$ & 5.50 & 4.00 & 4.00 & 4.00 & 4.00 & 6.00 & 1.10 \\
\hline & Mean & 3.67 & 2.27 & 1.27 & 0.67 & 2.53 & 3.07 & 0.34 \\
\hline & SD & 1.57 & 0.96 & 1.87 & 1.23 & 0.83 & 1.39 & 0.25 \\
\hline \multirow[t]{4}{*}{ HA } & Min & 1.00 & 1.50 & 0.00 & 0.00 & 1.00 & 1.00 & 0.00 \\
\hline & Max & 5.00 & 5.00 & 3.00 & 2.00 & 3.00 & 3.00 & 1.00 \\
\hline & Mean & 3.40 & 3.30 & 0.93 & 0.67 & 1.47 & 2.20 & 0.33 \\
\hline & SD & 1.26 & 1.08 & 0.96 & 0.72 & 0.64 & 1.01 & 0.36 \\
\hline
\end{tabular}

SLA - sandblasted and additionally etched implants, HA - hydroxyapatite

\section{DISCUSSION}

The criteria of success for implant treatment are differently formulated by various authors. According to Albrektsson, the success of implantological treatment is based, among others, on the MBL criterion. This loss, in the first year after the implantation, considered physiologically as a result of bone remodeling, should not exceed 1-2 mm and then in subsequent years, it should be no more than $0.2 \mathrm{~mm}$ per year [10]. Both G1 and G2 group of our study met the following criteria. The newer standards formulated by Buser indicate that the success in implantological treatment can be defined as the absence of implant's mobility, pain, paresthesia, and inflammatory process as well as lack of resorption features of the bone structure in direct vicinity of the implants [11], which was also found in our study for all implants.

On the seventh European Workshop on Periodontology, Lang and Berglundh established the criteria based on periodontal indexes, where ppd lower than $5 \mathrm{~mm}$ and absence of bleeding during probing can be considered as the lack of peri-implantitis. In our study, the highest ppd at 36 months of follow-up reported in our study was $4 \mathrm{~mm}$ accompanied with the absence of bleeding. All implants met mentioned criteria [12].

It should be noted that there is relatively small amount of publications on the subject of short dental implants' survival, and the results are additionally hindered by different methodologies adopted. Furthermore, the literature is dominated by the observation period shorter than three years, and the most commonly observed type of implants are SLA implants. Schincaglia [13] in a study on short SLA implants observed $\mathrm{MBL}$ at the level of $0.77 \pm 0.38 \mathrm{~mm}$ per year. In a recent report by Elsyad [14] with three years of observations, MBL value of $0.51 \pm 0.2 \mathrm{~mm}$ was observed. In the studies on short SLA implants ( $<6 \mathrm{~mm}$ length) and three-year observations, the MBL value was found from $1.28 \pm 0.37 \mathrm{~mm} \mathrm{[15]} \mathrm{to} 0.89 \pm 0.25 \mathrm{~mm} \mathrm{[16]}$.

Researches with a similar methodological approach, conducted on implants with hydroxyapatite coatings are even more rare. In such a study with annual observation, Kim et al. reported MBL value of $0.26 \pm 0.59 \mathrm{~mm}$ [17].

Generally, the literature is dominated by the opinion on the worse survival rates of short implants. In a study based on four-year observation, statistically more frequent failures were found when using implants shorter than $8.5 \mathrm{~mm}$ (2.9\% of lost implants) compared to implants longer than $10 \mathrm{~mm}$ (2.1\% of lost implants) [18]. These results were also confirmed by other authors $[19,20]$. However, it is worth to note of different studies with opposite results. Some authors indicate short implants as a predictable treatment option and a reasonable alternative to extensive regenerative procedures in patients with reduced volume of alveolar process $[19,21,22]$. According to Akram, short implants $(<6 \mathrm{~mm})$ with 3 years of observation period were characterized by $\mathrm{MBL}$ of $0.42 \mathrm{~mm}$ in the first year of follow-up after loading, and significantly reduced to $0.14 \mathrm{~mm}$ in the following third year, as PD slightly reduced from $2.6 \mathrm{~mm}$ at the baseline to $2.4 \mathrm{~mm}$ at the third year of follow-up; however, CAL increased from 3.8 to $4.5 \mathrm{~mm}$ during this follow-up [23]. Dierens performed a retrospective study on total 50 implants and reported that $91.5 \%$ of the implants had a mean interproximal probing depth of $<5 \mathrm{~mm}$ with $\mathrm{MBL}$ at $1.7 \mathrm{~mm}$ after the first year of loading [24]. Koldsland in the study with 8 years of follow-up reported that $23.1 \%$ of implants presented with PD above or equal to 4 or $6 \mathrm{~mm}$, and $8.2 \%$ of the implants showed bone loss of 2-3 $\mathrm{mm}$ and 3-4 $\mathrm{mm}$, respectively [25]. Abduljabar evaluated implants of the same that in present study size $(6 \times 4 \mathrm{~mm})$ with 3 years of observation period, reporting MBL of $1.1 \pm 0.2 \mathrm{~mm}$ and PD of $1.8 \pm 0.1 \mathrm{~mm}$ in non-smoking group of patients [26].

\section{CONCLUSIONS}

With the limitation of our study and 36 months of follow-up, short implants of both SLA and HA-coated surfaces can be considered as a reliable alternative to sinus-floor augmentation procedures and may be even preferred due to simplified protocol and reduced invasiveness. 


\section{CONFLICT OF INTEREST}

The authors declare no potential conflicts of interest with respect to the research, authorship, and/or publication of this article.

\section{References}

1. Guljé FL, Raghoebar GM, Vissink A, Meijer HJA. Single crowns in the resorbed posterior maxilla supported by either $11-\mathrm{mm}$ implants combined with sinus floor elevation or 6-mm implants: a 5-year randomised controlled trial. Int J Oral Implantol (New Malden) 2019; 12: 315-326.

2. Hansen EJ, Schou S, Harder F, Hjorting-Hansen E. Outcome of implant therapy involving localised lateral alveolar ridge and/or sinus floor augmentation: a clinical and radiographic retrospective 1-year study. Eur J Oral Implantol 2011; 4: 257-267.

3. Jurczyszyn K, Kubasiewicz-Ross P, Nawrot-Hadzik I, Gedrange T, Dominiak M, Hadzik J. Fractal dimension analysis a supplementary mathematical method for bone defect regeneration measurement. Ann Anat 2018; 219: 83-88.

4. Tawil G, Younan R. Clinical evaluation of short, machined-surface implants followed for 12 to 92 months. Int J Oral Maxillofac Implants 2003; 18: 894-901.

5. Wallace SS, Froum SJ. Effect of maxillary sinus augmentation on the survival of endosseous dental implants. A systematic review. Ann Periodontol 2003; 8: 328-343.

6. Nisand D, Renouard F. Short implant in limited bone volume. Periodontology 2000 2014; 66: 72-96.

7. Choi JY, Kang SH, Kim HY, Yeo IL. Control variable implants improve interpretation of surface modification and implant design effects on early bone responses: an in vivo study. Int J Oral Maxillofac Implants 2018; 33: 1033-1040.

8. Becker P, Neumann HG, Nebe B, Lüthen F, Rychly J. Cellular investigation on electrochemically deposited calcium phosphate composites. J Mater Sci Mater Med 2004; 15: 437-440.

9. De Groot K, Wolke JCG, Jansen JA. State of the art: hydroxyapatite coatings for dental implants. J Oral Implant 1994; 20: 232.

10. Albrektsson T, Zarb G, Worthington P, Eriksson AR. The longterm efficacy of currently used dental implants: a review and proposed criteria of success. Int J Oral Maxillofac Implants 1986; 1: 11-25.

11. Buser D, Schenk RK, Steinemann S, Fiorellini JP, Fox CH, Stich $\mathrm{H}$. Influence of surface characteristics on bone integration of titanium implants. A histomorphometric study in miniature pigs. J Biomed Mater Res 1991; 25: 889-902.

12. Lang NP, Berglundh T. Periimplant diseases: where are we now? consensus of the seventh european workshop on periodontology. J Clin Periodontol 2011; 38: 178-181.

13. Schincaglia GP, Marzola R, Giovanni GF, Chiara CS, Scotti R. Replacement of mandibular molars with single-unit restorations supported by wide-body implants: immediate versus delayed loading. A randomized controlled study. Int J Oral Maxillofac Implants 2008; 23: 474-480.

14. Elsyad MA, Al-Mahdy YF, Fouad MM. Marginal bone loss adjacent to conventional and immediate loaded two implants supporting a ball-retained mandibular overdenture: a 3-year randomized clinical trial. Clin Oral Implants Res 2012; 23: 496-503.

15. Pistilli R, Felice P, Cannizzaro G, et al. Posterior atrophic jaws rehabilitated with prostheses supported by $6 \mathrm{MM}$ long $\times 4 \mathrm{MM}$ wide implants or by longer implants in augmented bone. 3-year post-loading results from a randomised controlled trial. Eur J Oral Implantol 2013; 6: 359-372.

16. Gastaldi G, Felice P, Pistilli R, Barausse C, Trullenque-Eriksson A, Esposito M. Short implants as an alternative to crestal sinus lift: a 3-year multicentre randomised controlled trial. Eur J Oral Implantol 2017; 10: 391-400.
17. Kim YK, Ahn KJ, Yun PY, et al. Effect of loading time on marginal bone loss around hydroxyapatite-coated implants. J Korean Assoc Oral Maxillofac Surg 2013; 39: 161-167.

18. Castellanos-Cosano L, Rodriguez-Perez A, Spinato S, Wainwright M, Machuca-Portillo G, Serrera-Figallo MA, Torres-Lagares D. Descriptive retrospective study analyzing relevant factors related to dental implant failure. Med Oral Patol Oral Cir Bucal 2019; 24: 726-738.

19. Cabrera-Domínguez J, Castellanos-Cosano L, Torres-Lagares D, Machuca-Portillo G. A prospective case-control clinical study of titanium-zirconium alloy implants with a hydrophilic surface in patients with type 2 diabetes mellitus. Int J Oral Maxillofac Implants 2017; 32: 1135-1144.

20. Mezzomo LA, Miller R, Triches D, Alonso F, Shinkai RS. Metaanalysis of single crowns supported by short $(<10 \mathrm{~mm})$ implants in the posterior region. J Clin Periodontol 2014; 41: 191-213.

21. Misch CM, Polido WD. A "graft less" approach for dental implant placement in posterior edentulous sites. Int J Periodontics Restorative Dent 2019; 39: 771-779.

22. Esposito M, Pistilli R, Barausse C, Felice P. Three-year results from a randomised controlled trial comparing prostheses supported by 5-mm long implants or by longer implants in augmented bone in posterior atrophic edentulous jaws. Eur J Oral Implantol 2014 Winter; 7: 383-395.

23. Akram Z, Vohra F, Sheikh SA, Albaijan R, Bukhari IA, Hussain M. Clinical and radiographic peri-implant outcomes of short dental implants placed in posterior jaws of patients with treated generalized aggressive periodontitis: a 3-year follow-up study. Clin Implant Dent Relat Res 2019; 21: 775-780.

24. Dierens M, Vandeweghe S, Kisch J, Nilner K, De Bruyn H. Longterm follow-up of turned single implants placed in periodontally healthy patients after 16-22 years: radiographic and peri-implant outcome. Clin Oral Implants Res 2012; 23: 197-204.

25. Koldsland OC, Scheie AA, Aass AM. Prevalence of periimplantitis related to severity of the disease with different degrees of bone loss. J Periodontol 2010; 81: 231-238.

26. Abduljabbar T, Al-Hamoudi N, Al-Sowygh ZH, Alajmi M, Javed F, Vohra F. Comparison of peri-implant clinical and radiographic status around short (6 $\mathrm{mm}$ in length) dental implants placed in cigarette-smokers and never-smokers: Six-year follow-up results. Clin Implant Dent Relat Res 2018; 20: 21-25. 